\title{
O ENFERMEIRO NA PRÁTICA DOCENTE: REFLETINDO SOBRE OS MÉTODOS DE AVALIAÇÃO DO ENSINO E APRENDIZAGEM
}

Jamila de Souza GONÇALVES

Ana Leticia Carnevalli MOTTA ${ }^{1}$

Ana Cristina Gonçalves de Abreu SOUZA ${ }^{2}$

Zélia Marilda Rodrigues RESCK²

Elisa Maria Resende DÁZIO²

\begin{abstract}
${ }^{1}$ Mestranda pelo Programa de Pós-Graduação da Escola de Enfermagem da Universidade Federal de Alfenas. UNIFAL - MG. Brasil.

${ }^{2}$ Professora Doutora do Programa de Pós-Graduação da Escola de Enfermagem da Universidade Federal de Alfenas.

UNIFAL - MG. Brasil. eliza.dazio@unifal-mg.edu.br
\end{abstract}

Recebido em: 13/05/2014 - Aprovado em: 30/06/2014 - Disponibilizado em: 30/07/2014

\section{RESUMO:}

Este artigo apresenta uma reflexão sobre a prática de avaliação no ensino superior em enfermagem. A avaliação constitui importante ferramenta para acompanhamento do processo de ensino e aprendizagem quando utilizada como diagnóstico norteador para intervenções e melhorias no desenvolvimento de atividades educacionais. A realidade nos mostra a aplicação de métodos de avaliação usados com ênfase na quantificação dos resultados por meio de notas e não como sistema de avaliação da qualidade do processo ensino aprendizagem. Repensar as formas de avaliação aplicadas no cotidiano do enfermeiro professor, é criar oportunidade para contribuir com a formação dos profissionais de enfermagem para a construção de seu conhecimento.

Descritores: enfermagem; ensino; aprendizagem; avaliação.

\section{ABSTRACT :}

This article focuses on assessment practice in higher education in nursing. The assessment is an important tool for monitoring the teaching and learning process when used as a guide for diagnostic interventions and improvements in the development of educational activities. Reality shows in the application of valuation methods used with emphasis on measuring outcomes through notes and not as an evaluation system of teaching quality learning process. Rethinking forms of assessment applied in daily nursing teacher, is to create an opportunity to contribute to the training of nursing professionals to build their knowledge.

Keywords: nursing; education; learning; Review

\section{INTRODUÇÃO}

A prática de avaliação é constante no trabalho profissional nas diversas áreas, dentre elas, na enfermagem. De modo geral, as atividades realizadas pelos sujeitos são um objeto de avaliação, e intencionalmente ou não todas as ações estão sujeitas a algum tipo de julgo popular ou acadêmico, de uma comparação ou conclusão; e a partir destas, as decisões em nosso cotidiano são tomadas (BACKES, 2010).
O processo de avaliação, numa visão tradicional, vem sendo construído ao longo de sua historia e sua principal finalidade é a capacidade de aprovar e reprovar alunos, refletindo na vida das pessoas como status e ascensão social. No século XVI e XVII surge nas escolas modernas a prática de avaliação por meio de provas e exames. No século XVI, surge a pedagogia jesuítica, rigorosa e com bases católicas voltando especial atenção ao ritual de provas e exames. Havia bancas examinadoras públicas onde nas sessões solenes todos eram comunicados sobre os 
resultados individuais No século XVII a pedagogia comeniana, preocupa- se com o professor mas ainda utiliza exames como métodos avaliativos ( FENILI, 2002).

A trajetória histórica nos apresenta a utilização de um tipo de avaliação na educação, em que as provas e os exames oriundos da escola jesuítica tinham o objetivo de converter e doutrinar com base no catolicismo os indivíduos transviados e desviados dos caminhos propostos pela igreja. A escola cristã permaneceu no Brasil de 1549 a 1759 com exercícios de fixação e memorização onde os alunos em destaque eram auxiliares dos professores revendo e tomando as lições dos alunos considerados fracos. Desta prática originou o termo sabatina, termo por muito tempo utilizado no meio acadêmico como sinônimo de avaliação ( SAVIANI, 2005 ).

A avaliação dos alunos pelo professor é que determina a classificação das condições da aprendizagem e permite que sejam interpretados seus modos de conduta e seus conhecimentos, possibilitando uma melhoria das atividades escolares e educacionais. Ainda, dentro desta ação, a observação prolongada do comportamento dos alunos durante o ensino é imprescindível para possibilitar o levantamento de dados escritos, amnésicos e pessoais fornecendo subsídios a definição do comportamento dos mesmos (IPFLING, 1974).

\footnotetext{
"A avaliação é uma ferramenta a qual o ser humano não se livra. Ela faz parte de seu modo de agir e, por isso, é necessário que seja usada da melhor forma possível"

( LUCKESI, 2002, p.118 )
}

A partir da literatura é possível encontrar uma pluralidade de conceitos para a avaliação, considerando que há diversidade entre os posicionamentos, o que demanda compreender diferentes paradigmas e os posicionamentos dos sujeitos. Diferentes autores propõem diversas definições para esta prática. Alguns conceituaram na literatura antiga, a avaliação de forma limitada, ou seja, reduziram o conceito à valoração dos resultados obtidos pelos alunos. Já nas definições contemporâneas a avaliação ganha diferente conotação, ela faz parte de um processo de construção pedagógica de ensino aprendizagem, num contexto mais abrangente, onde alunos e professores interagem e são simultaneamente avaliados.

Sendo a avaliação importante prática inerente à competência gerencial do (a) enfermeiro (a), estes avaliam diariamente a execução do trabalho junto aos seus colaboradores, em cumprimento a atribuição legal que lhe foi conferida na legislação vigente que determina o exercício profissional da enfermagem Lei n $^{\text {0 } 7.478}$ de 25 de abril de 1986. Esta Lei dispõe sobre a regulamentação do exercício da enfermagem, e dá outras providências; parágrafo único; Art. 11: O Enfermeiro exerce todas as atividades de enfermagem, cabendo-lhe: I - privativamente; c) planejamento, organização, coordenação, execução e avaliação dos serviços da assistência de enfermagem.

Executar práticas avaliativas faz parte do cotidiano do profissional enfermeiro dentro das comunidades, das instituições de saúde e na atividade docente; sendo esta prática docente o enfoque da reflexão proposta neste estudo, os profissionais, a voltar sua atenção ao modo como o enfermeiro docente, tem exercitado a avaliação do ensino e aprendizagem na prática docente.

\section{DIRETRIZES VIGENTES E CONCEITOS DE AVALIAÇÃO}

O curso de graduação em Enfermagem faz parte de uma gama de cursos de formação superior norteados por diretrizes determinadas pelo Ministério da Educação que embasam a prática docente do enfermeiro e demais profissionais. Especificamente dispomos da Resolução CNE/CES No $\mathbf{3}$, de 7 de novembro de 2001. Institui Diretrizes Curriculares Nacionais do Curso de Graduação em Enfermagem, que no ítem 3, Conteúdos Curriculares do Curso de 
Graduação em Enfermagem, consta à capacitação pedagógica do enfermeiro, independente da Licenciatura em Enfermagem e para o Acompanhamento e Avaliação desta prática, ítem 6, esclarece sobre a implantação e desenvolvimento das diretrizes curriculares de enfermagem, que deverão ser acompanhados e permanentemente avaliados, a fim de permitir os ajustes que se fizerem necessários a sua contextualização e aperfeiçoamento.

As avaliações somativa e formativa do aluno deverão basear-se nas competências, habilidades e conteúdos curriculares. O Curso de Graduação em Enfermagem deverá utilizar metodologias e critérios para acompanhamento e avaliação do processo ensinoaprendizagem e do próprio curso, em consonância com o sistema de avaliação definido pela instituição de ensino em saúde à qual pertence.

De modo geral, a avaliação faz parte do processo educativo estando vinculada aos resultados obtidos na aprendizagem. Para a prática avaliativa é preciso lançar mão dos recursos legais de forma a atender as exigências qualitativas nas ações da demanda pedagógica. A Legislação vigente, de modo geral, dispõe de Leis das Diretrizes e Bases da Educação Nacional - Lei $n^{0}$ 9.394, de 20 de dezembro de 1996; esta contempla a avaliação no art.

24, transcrito a seguir:

“Art. 24: A educação básica, nos níveis fundamental e médio, será organizada de acordo com as seguintes regras comuns: [...] V- a verificação do rendimento escolar observará os seguintes critérios".

a) A avaliação contínua e cumulativa do desempenho do aluno, com prevalência dos aspectos qualitativos sobre os quantitativos e dos resultados ao longo do período sobre os de eventuais provas finais;

A avaliação até os dias de hoje realizada nas escolas é aplicada de forma classificatória por meio de provas e resultados de notas. Esta prática, quase sempre, estará fadada ao fracasso atribuído aos alunos, por um grande equivoco, considerando que a construção do processo ensino aprendizagem se estabelece a partir das relações que profissionais de educação, alunos e pais estabelecem entre si

Diversos são os autores que definem a avaliação da aprendizagem, dentre estas encontramos a concepção de avaliação emancipatória que afirma o processo como a tomada de determinada decisão partindo da avaliação sobre a qualidade dos dados relevantes, ressaltando que o ato de avaliar ainda tem conotação classificatória não sendo utilizada como método diagnóstico, de forma a possibilitar um diálogo entre os participantes do processo educacional em prol de seu desenvolvimento e construção. Considera que a avaliação como é, conservadora, tem papel disciplinador tendo o professor livre arbítrio para decidir e estabelecer a avaliação do aluno, considerando o uso de "médias" de notas, criando- se um padrão de organização e orientação ( LUCKESI, 1995 )

Ainda, a prática da avaliação não se limita a classificação por nota, esta prática é dinâmica e pactuada entre a relação aluno e professor, cada um desempenhando seu papel de forma co- relacionada e co- participativa, onde o diálogo entre ambos permite a construção do processo de ensino aprendizagem baseado em respeito e favorecendo a formação de um profissional competente ( SORDI, 1995 ).

A avaliação da aprendizagem intervém na construção do currículo e está relacionada a todo o processo de gerenciamento da aprendizagem. Docentes devem se preocupar para que a educação seja excelente, que a aplicação de provas não tenha cunho classificatório, mas, diagnóstico. Somente assim resultados verídicos sobre aprendizagem serão coletados ( PERRENOUD, 1999).

\section{LUCKESI E A PRÁTICA DE VERIFICAÇÃO E AVALIAÇÃO NA ESCOLA}

Cipriano Carlos Luckesi, professor de Filosofia da Educação, referencial teórico importante na temática da avaliação, nos leva a reflexão sobre o caminho pelo qual estamos conduzindo o processo 
ensino - aprendizagem tendo como base textual uma abordagem sobre a prática de aferição do aproveitamento escolar e utiliza como matriz os conceitos de verificação e avaliação, por ele definidos como sendo o conceito verificação que emerge das determinações da conduta de, intencionalmente, buscar "ver se algo é isso mesmo...", "investigar a verdade de alguma coisa:" A verificação surge das determinações de condutas intencionais; e caracteriza - se pela análise e pelo compilar dos dados ou das informações colhidas delimitando o objeto de estudo.

A verificação é finalizada no momento em que se obtém a informação e o objeto de busca, basta visualizar que estará definido; e se inicia a partir das determinações de conduta para valoração da qualidade de algo, não devendo ser o ato de avaliar medido em quantidade. A avaliação se forma a partir das determinações de conduta atribuindo valores ou qualidades ao objeto que está sendo avaliado (LUCKESI, 1995).

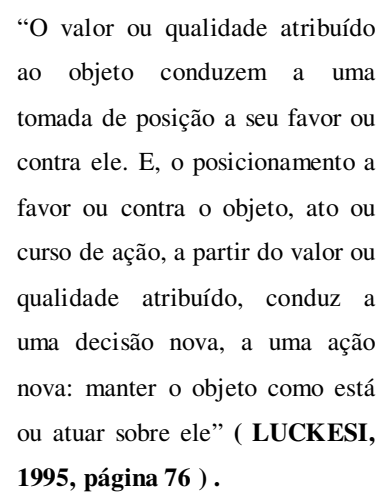

$\mathrm{O}$ autor afirma para que os resultados da aprendizagem sejam positivos é fundamental que o foco da avaliação escolar esteja na qualidade dos processos de ensino e aprendizagem e propõe que o professor, ao avaliar, fugindo do aspecto classificatório deverá: desenvolver a partir das condutas cognitivas, afetivas, psicomotoras - dos educandos, produzindo uma configuração do efetivamente aprendido; atribuir uma qualidade a essa configuração da aprendizagem, a partir de um padrão (nível de expectativa) preestabelecido e admitido como válido pela comunidade dos educadores e especialistas dos conteúdos que estejam sendo trabalhados; a partir dessa qualificação, tomar uma decisão sobre as condutas docentes e discentes a serem seguidas, tendo em vista: - a reorientação imediata da aprendizagem, caso sua qualidade se mostre insatisfatória e o conteúdo, habilidade ou hábito, que esteja sendo ensinado e aprendido, seja efetivamente essencial para a formação do educando; - o encaminhamento dos educandos para passos subseqüentes da aprendizagem, caso se considere que, qualitativamente, atingiram um nível satisfatório que estava sendo trabalhado.

Deste modo o autor considera fundamental que o objeto da aferição do aproveitamento escolar não tenha como enfoque a quantificação por notas, em consequência a aprovação ou reprovação do aluno, e sim, intervenções com tomadas de decisões a partir de instrumentos que considerem todos os processos de ensinar e aprender e seus resultados para a formação do aluno.

\section{CONSIDERAÇÕES FINAIS}

A avaliação é tema de discussão constante no meio acadêmico, e mesmo em uma época pósmoderna, frente ao acesso ilimitado à informação, usada para a construção de conhecimentos, ainda é tema complexo, por se tratar de um objeto de conhecimento que emerge de conceitos arraigados influenciados por paradigmas conservadores e que se desdobram a partir de diversas questões históricas, políticas e sociais.

O termo avaliar causa grande preocupação sendo usado a fim de mensurar resultados em notas e não em medir a eficiência dos processos de ensino e aprendizagem no qual, docentes, discentes e comunidade estão envolvidos.

Não somente na avaliação da aprendizagem, como também nas avaliações de projetos, cursos, dentre outros, onde, uma das grandes preocupações sempre é o que vão fazer com o resultado da avaliação. 
A ação de avaliar está presente na prática docente sendo o educador submetido a uma ação avaliativa que nos reporta a diversos questionamentos quanto a sua efetividade. A reflexão sobre o processo de avaliação deve ser constante no cotidiano do enfermeiro professor, se importante mobilizar- se diante da prática predominante pela imposição do sistema de notas a fim de questionar e propor novas diretrizes, numa vez que o aluno do curso de graduação em enfermagem deverá estar apto a cuidar de outro ser humano, cuidar em acordo com a polissemia do termo, em amplitude e profundidade.

Avaliar demanda reconhecer processos e os desdobramentos de intervenção que decorrem dos instrumentos desenvolvidos com cada sujeito envolvido com o conhecimento específico proposto no universo educacional.

\section{REFERÊNCIAS}

BACKES; D.,D., B. Avaliação do Processo Ensino Aprendizagem: conceitos e concepções. $\quad[\quad$ acesso: www.nre.seed.pr.gov.br/cascavel/arquivos/Fil e/.../producao_dorimar.pdf em 24.04.2014]

FENILI, R. M.; OLIVEIRA, M. E.; SANTOS;M. B.; ECKERT, E. R. Repesando a avaliação da aprendizagem. Revista Eletrônica de Enfermagem. vol. 4, $\mathrm{n}^{\circ} 2$, p. 42 - 48. 2002. Disponível em http://www.fen.ufg.br

SAVIANI, D. As concepções pedagógicas na história da educação brasileira. Campinas: Histebdr, 2005. ( Projeto de Pesquisa “O espaço acadêmico da pedagogia no Brasil)

IPFLING, H. Vocabulário Fundamental de pedagogia. Lisboa: Edições 70, 1974.
LUCKESI, C.C. Avaliação da Aprendizagem Escolar: estudos e proposições, 14 ed. São Paulo: Cortez, 2002.

LEI N 7.478 de 25 de abril de 1986 . [acesso http: novo.portalcofen.org.br, 28.04.2010]

RESOLUÇÃO CNE/CES $\mathbf{N}^{\circ} 3$, de 7 de novembro de 2001. Institui Diretrizes

Curriculares Nacionais do Curso de Graduação em Enfermagem. [acesso http: portal.mec.gov.br/cne/arquivos/pdf/CES03.pd f].

\section{Leis das Diretrizes e Bases da Educação} Nacional - Lei $n^{\circ}$ 9.394, de 20 de dezembro de 1996; esta contempla a avaliação no art. 24. [

www.planalto.gov.br/ccivil_03/leis/19394.htm ]

LUCKESI; C. C. Avaliação da aprendizagem escolar. São Paulo: Cortez, 1995.

SORDI; M.R. A prática de avaliação do ensino superior: uma experiência na enfermagem. São Paulo: Cortez PUCCAMP, 1995.

PERRENOUD, P. Avaliação: da Excelência à regulação das aprendizagens entre duas lógicas. Porto Alegre: Artmed Editora; 1999. 